\title{
SOBRE LA LIBERTAD
}

\section{EN LA VIDA ES SUEÑO ${ }^{22}$}

\section{Consideraciones teológicas}

Reconocidos críticos, como Marcelino Menéndez Pelayo, han señalado que la tragicomedia La vida es sueño de Pedro Calderón de la Barca tiene como uno de sus ejes conceptuales la defensa de la doctrina del libre albedrío en la versión elaborada por la Contrarreforma. Esto, sin duda, es cierto. No podemos olvidar que, en Madrid, Calderón de la Barca estudió en el Colegio Imperial de la Compañía de Jesús de la Villa y Corte, entre los años 1608 y 1613. Sus estudios estaban encaminados a prepararlo para el sacerdocio, lo que solo vino a acontecer a mediados del siglo XVII, cuando Calderón de la Barca ingresó a la Orden de los Frailes Menores o franciscanos. Después del Concilio de Trento (1545-1563), la Compañía de Jesús -fundada en 1540- nunca dejaría de demostrar su compromiso práctico y teórico con las doctrinas de la Contrarreforma establecidas por ese concilio, doctrinas que Calderón debió asimilar durante sus años de formación con los jesuitas.

22 El texto fue elaborado a petición del profesor y amigo Andrés Lema-Hincapié, para una obra conjunta que deberá aparecer en inglés. Debo agradecerle toda una serie de observaciones muy acertadas, que espero haber tenido muy en cuenta. 
Sin embargo, como justamente aseguran Edward M. Wilson y Joaquín Casalduero, La vida es sueño "no pertenece al llamado teatro de tesis o de ideas; pero tiene una teoría de la vida como fondo. De aquí que reconozcamos en la comedia todos los lugares comunes del cristianismo: la caída del hombre, su libertad, la temporalidad del mundo, la mentira de la vida" (1979, p. 783). En todo caso, para comprender mejor el sentido que Calderón de la Barca quiso darle a su pieza de teatro -es decir, la "teoría de la vida" que ella tiene de fondo-, pienso que conviene situarla en el contexto de las álgidas discusiones en torno al concepto de libre albedrío que impregnaron sin duda el ambiente de esa época. En razón de las críticas elaboradas por Martín Lutero (1483-1546) en contra de la realidad efectiva de ese concepto para la voluntad humana, las controversias habían logrado que el libre albedrío se situara en el centro de los debates teológicos dentro de la misma teología católica. Esto puede constatarse con gran claridad en las fuertes querellas que tuvieron lugar entre teólogos de la Orden de Santo Domingo de Guzmán -dominicos- y miembros de la Compañía de Jesús -jesuitas- en torno de la doctrina llamada de la "ciencia media". Este enfrentamiento se conoce como la disputatio de auxiliis, esto es, las discusiones en torno al papel que desempeña la gracia divina en el obrar humano y el conocimiento que Dios tiene de nuestras acciones. El dilema que se les planteaba a los teólogos era el siguiente: si Dios conoce previamente los pecados de los seres humanos y nos los evita, entonces o no es bueno o no es omnipotente; y si no los conoce previamente, entonces no es omnisciente.

Para buscar una salida al dilema, el jesuita Luis de Molina (1533-1600) propone un tercer género de conocimiento divino, diferente de los dos que reconocía la tradición. Los conceptos tradicionales eran: (a) la "ciencia de simple inteligencia", por la cual Dios conoce las cosas con independencia de su existencia concreta, es decir, en sus esencias eternas, y (b) la "ciencia de visión", por la cual conoce las realidades efectivas en su misma singularidad espacio temporal. En su obra titulada Liberi arbitrii cum gratiae donis, divina praescientia, providentia, praedestinatione et reprobatione concordia (Concordia del libre albedrío con los dones de la gracia, la divina presciencia, providencia, predestinación y reprobación) de 1588, Molina propone una tercera forma de conocimiento divino a la que llama "ciencia media", gracias 
a la cual Dios conoce los llamados "futuribles", es decir, aquellas realidades que, como los actos humanos, pueden llegar a suceder o no suceder, sin que obedezcan a una necesidad que los preceda. En estos casos, Dios, quien se halla por fuera de la temporalidad, conoce el acto en su mismo acontecer, pero sin que tal conocimiento pueda considerarse anterior o posterior al acto como tal. Tenemos así tres clases de conocimiento divino, de acuerdo con los objetos de dicho conocimiento: en el caso de las esencias eternas de todas las cosas, Dios las conoce por "ciencia de simple inteligencia"; en el caso de las existencias de las cosas contingentes, pero sujetas a la necesidad causal, Dios las conoce por "ciencia de visión"; y en el caso de las acciones humanas que, si bien son contingentes, no están sin embargo sometidas a la causalidad natural, sino que dependen del libre albedrío, Dios las conoce en su misma existencia puntual gracias a esa "ciencia media". Se trata de un conocimiento que se sitúa en un 'término medio' entre la eternidad de las esencias y la temporalidad de las existencias. En otras palabras, no podemos decir que Dios conozca nuestros actos libres desde toda la eternidad, porque ello implicaría una suerte de predestinación; pero tampoco podemos decir que Dios deba esperar a que nosotros actuemos para saber lo que vamos a hacer, porque eso sería someter a Dios a las condiciones de lo contingente. Entonces, como no podemos pensar que Dios esté condicionado por el tiempo, cabe pensar que conoce nuestros actos, no antes pero tampoco después de que nosotros los hayamos ejecutado, sino en acto mismo.

Con ello buscaba el teólogo jesuita escapar a la posición determinista que sustentaban los reformadores Lutero y Calvino, con su doctrina de la predestinación, según la cual Dios, desde la eternidad, destinaba a los seres humanos ya sea para la salvación, ya para la condenación. Los jesuitas consideraban que en esta misma predestinación venía a desembocar la doctrina sustentada por los dominicos en la persona del teólogo Domingo Báñez (1528-1604) $)^{23}$.

Cabría decir que, en la obra de Calderón, el rey Basilio viene a representar la doctrina de la predestinación, al haber creído en los presagios según los cuales su hijo Segismundo llegaría a ser inexorablemente un parricida y un soberano lleno de maldad con sus súbditos. Presagio que pareciera

23 Un estudio detallado de esta controversia, junto con los textos y documentos más significativos, puede encontrarse en el libro de Vicente Beltrán de Heredia, Domingo Báñez y las controversias sobre la gracia (ver Bibliografía). 
confirmarse en un primer momento, cuando Segismundo es liberado de sus cadenas y comienza a gobernar de manera injusta y caprichosa.

De esa manera, en contra del rey Basilio -una suerte de máscara teatral para Lutero, y acaso también para el reformador Calvino (1509-1564), e incluso para el teólogo dominico Domingo Báñez-, Calderón de la Barca dramatiza en Segismundo la realidad del libre albedrío defendida por Molina, al negar el carácter inevitable de los presagios agoreros y sobreponerse libremente a lo que parecía ser un destino inexorable.

Por la voz de Rosaura, en las décimas que abren la Primera Jornada del drama, el fatalismo antropológico sobre la voluntad humana parece estar acuñado en versos. Ella le habla a un tú imaginario y lo increpa. Ese tú -"Hipogrifo violento / que corriste parejas con el viento" (I, vv. 1, 2)- es, probablemente, una anticipación todavía no vista de Segismundo y, a su vez, en su calidad de símbolo dramático, de la voluntad humana. Segismundo encarnaría por sinécdoque también a la voluntad de la misma Rosaura. Carente de fuerzas morales, después de la caída mortal en razón del pecado original de Adán y Eva, la voluntad humana es un tú-como lo son igualmente todo espectador y todo lector de la obra-, especie de engendro monstruoso e imposible, una contradicción existente que "al confuso laberinto / de esas desnudas peñas / te desbocas, / te arrastras y despeñas" (I, vv. 6-8). Y, de inmediato, el tú se transmuta rápidamente en el yo de Rosaura: "yo, sin más camino/ que el que me dan las leyes del destino" (I, vv. 11, 12). En el tú imaginario y en el yo de Rosaura, Calderón de la Barca habría caracterizado la posición de un primer bando de querellantes: aquellos que niegan el libre albedrío y afirman la absoluta necesidad de la gratia Dei: San Agustín de Hipona (354-430), Martín Lutero y Domingo Báñez.

\section{La controversia sobre el libre albedrío: filosofía y teología}

Comencemos por precisar lo que se entiende por "libre albedrío" y los problemas teológicos que conlleva este concepto. Para ello, es conveniente señalar que se trata de una verdadera novedad en el pensamiento occidental. Esta novedad es un aporte del judeocristianismo a partir de su concepción del pecado. Como lo muestra Claudio Palavecino en su artículo "Culpa 
y castigo en la antigua Grecia", aunque los pensadores griegos pudieron llegar a tener una cierta idea de culpa personal, no cabe duda de que fue bajo la influencia sobre todo de la doctrina cristiana que el concepto llegó a alcanzar toda esa fuerza con la que ha marcado de manera imborrable las raíces mismas del pensamiento de Occidente. En efecto, los griegos de la Antigüedad no elaboraron nunca la idea de la voluntad en cuanto facultad humana que pudiera obrar con absoluta autonomía, es decir, al margen o en contra de los dictados de la razón. Para los antiguos griegos, cuando una persona se comportaba de manera reprochable, es decir, cuando obraba en contra de lo que dictaba la razón, ello era debido a una de dos posibles causas: o bien su intelecto se hallaba obnubilado y entendía mal lo que le dictaba su razón -lo que constituía un error craso (omnis peccans est ignorans -todo pecador es ignorante-, rezaba un viejo adagio de origen aristotélico); o bien las pasiones de un individuo eran tan fuertes que su razón no lograba dominarlas. En uno y otro caso, por igual, no había una culpa strictu sensu, sino ignorancia o debilidad. Atribuir ignorancia o atribuir debilidad como causas de la acción reprochable no disminuía, por supuesto y eo ipso, el carácter reprochable de esa misma acción.

Como lo ha señalado muy bien Hannah Arendt, esas dos formas de comprender las acciones humanas que merecen reproche -desde la ignorancia o desde la debilidad- se ven reflejadas en el intelectualismo moral de Sócrates y en la ética aristotélica, respectivamente ${ }^{24}$. Y en cuanto a la forma en que estas doctrinas se veían reflejadas en la vida ordinaria, podemos recordar el estudio ya canónico de E. R. Dodds, Los griegos y lo irracional, donde se muestra cómo la mitología griega disponía de una deidad llamada Ate o Atea (insensatez, engaño), diosa de la fatalidad, que se apoderaba de los seres humanos cuando estos perdían el control de sus actos, y era ella la que los llevaba a cometer acciones reprochables ${ }^{25}$. Obrar de manera reprochable era entonces una muestra de ignorancia o de debilidad, pero no propiamente una culpa moral.

Segismundo, por el contrario, tiene conciencia del pecado original, es decir, de cargar con una culpa por el solo hecho de haber nacido:

24 Ver la segunda parte de su obra La vida del espíritu, titulada "La voluntad”, pp. 237 y ss. 25 Ver sobre todo el capítulo I de La explicación de Agamenón, pp. 13 y ss. 
Aunque, si nací, ya entiendo

qué delito he cometido;

bastante causa ha tenido

vuestra justicia y rigor,

pues el delito mayor

del hombre es haber nacido (I, vv. 107-112).

Sin embargo, durante buena parte de la obra, su comportamiento parece obedecer a las implacables determinaciones del destino, tal como lo ha temido su padre Basilio; incluso cuando, en la Jornada Segunda y con un gesto de paternal compasión, intenta probar a su hijo haciéndolo "soñar" que ha sido nombrado soberano del reino.

Ahora bien, con la introducción dela idea de pecado, el judeocristianismo introdujo un concepto que había de tener muy profundas e inesperadas consecuencias en el desarrollo de la cultura de Occidente, porque con él viene unida, de manera indisoluble, la idea de una responsabilidad personal intransferible; responsabilidad personal que constituye a la vez la grandeza de los seres humanos, su carácter de personas libres, e igualmente la fuente de sus más profundas miserias, su capacidad de obrar el mal, de ser perversos.

Si queremos buscar una definición clara de pecado, no parece haber mejor recurso que acudir a su clásica definición formulada por el Catecismo de la doctrina cristiana (1599), escrito por el jesuita Gaspar Astete (15371601). En el mundo católico de habla hispana, esta obra vino a ser, para muchas generaciones, el referente obligado de todo creyente, ya que en ella Astete había logrado resumir de manera magistral, en un estilo impecable de grata sonoridad, las doctrinas centrales del catolicismo tridentino. A la pregunta: “¿Qué es pecado mortal?”, responde el catecismo: “Pecado mortal es decir, hacer, pensar o desear algo contra la ley de Dios o la ley humana en materia grave, con plena advertencia y pleno consentimiento" (Astete, 1936, p. 30). La pregunta que surge entonces viene a ser: ¿puede en realidad una voluntad humana obrar con plena advertencia y pleno consentimiento aquello que su razón le muestra que es inaceptable? ${ }^{26}$.

26 Sobre este problema y su relación con el mal, cabe remitir al excelente libro del teólogo jesuita Carlos Bravo: El problema del mal. Se trata de una obra que su autor no alcanzó a publicar, y que fue editada y publicada por el también teólogo y jesuita Germán Neira. 
Porque, en los términos de la filosofía escolástica de raigambre aristotélica, no parece que una facultad como la voluntad humana pueda pasar de la potencia al acto, es decir, pueda entrar a decidir, si el entendimiento no le presenta algo que atraiga su deseo. Y solo puede atraer el deseo de la voluntad aquello que por su naturaleza sea deseable. Ahora bien, como el mal por su misma naturaleza es lo indeseable, no puede, como tal, ser el objeto de la voluntad. Por eso, cuando la voluntad parece desear algo malo, solo puede hacerlo en la medida en que lo considere bueno, es decir, que lo considere deseable: sub specie boni (bajo la figura de lo bueno). De ahí proviene el adagio que mencioné anteriormente: todo pecador es ignorante.

Por eso, si utilizamos las nociones clásicas de la escolástica, me parece que las encrucijadas teológicas y antropológicas dramatizadas en La vida es sueño se pueden ver con mayor claridad. Para ello, importa examinar conceptualmente el triángulo $\mathrm{mal} / \mathrm{voluntad} / \mathrm{bien}$. Empecemos con el concepto de mal. Como acabamos de señalar, si el mal es aquello que por su naturaleza es no deseable, no se ve cómo la voluntad pudiera llegar a desearlo - porque la voluntad debe ser considerada como una facultad o una capacidad que se halla en potencia, es decir, que puede obrar. En segundo lugar, una facultad en potencia necesita una razón o un motivo que explique el paso de la potencia al acto. En el caso de un acto conforme a la razón, el paso puede justificarse plenamente, porque la razón le muestra a la voluntad lo bueno como deseable, y ésta procede a desearlo. Y, en tercer lugar, en el caso del acto reprochable, la razón le muestra a la voluntad algo no deseable. ¿Cómo puede entonces la voluntad desear lo no deseable? La única explicación posible sería un acto caprichoso, pero esto implicaría un acto sin explicación alguna posible, es decir, un mero porque sí sin justificación de ninguna especie. Y esto no se ve cómo pueda aceptarlo la razón.

Si ahora nos fijamos en La vida es sueño, vemos que Segismundo sabe que no solo puede desear el mal, incluso de manera repetida, sino que así mismo puede realizarlo. En el intercambio de coquetería y de rechazo entre Rosaura y Segismundo, por ejemplo, éste último la amenaza si no responde positivamente a sus requiebros amorosos. Ni la belleza de Rosaura puede protegerla de un acto malo sobre ella. Ese acto malo Segismundo lo entiende como algo imposible y, no obstante, realizable. Aquí está la amenaza de una voluntad que puede obrar el mal: 
Sólo por ver si puedo,

harás que pierda a tu hermosura el miedo;

que soy muy inclinado

a vencer lo imposible. Hoy he arrojado

de ese balcón a un hombre que decía

que hacerse no podía;

y así, por ver si puedo, cosa es llana

que arrojaré tu honor por la ventana (II, vv. 653-660).

En la historia del pensamiento, hay un caso de particular significación, cuando se trata de examinar el problema que presenta la idea cristiana de libre albedrío, y es precisamente la doctrina del filósofo judío-holandés Baruch Spinoza (1632-1677), contemporáneo de Calderón. Este filósofo dedicó las dos primeras partes de su gran obra, Ética demostrada según el orden geométrico, a demostrar, con sumo cuidado, que el libre albedrío no puede darse ni en Dios ni en los seres humanos. Según sus razonamientos, se trata de un concepto tan imposible como el de un círculo cuadrado, porque significa que la acción de la voluntad se lleva a cabo sin causa ni explicación alguna. Y un acto así resulta simplemente inconcebible para la razón.

Es justo señalar que los pensadores escolásticos no ignoraron estos problemas, y que buscaron estudiarlos con toda la seriedad posible. Solo que para ellos, como hemos tenido ocasión de verlo, dado que se trataba de buenos creyentes, el problema venía a complicarse aún más con la idea de un Dios omnipotente y omnisciente, a la vez que infinitamente misericordioso. Para el concepto de un Dios así, la existencia del mal en general, y sobre todo del mal moral, es decir, la existencia de la perversidad humana, resulta muy difícil de explicar. Recordemos la clásica formulación del problema para los teólogos: si Dios conoce previamente los pecados de los seres humanos y nos los evita, entonces o no es bueno o no es omnipotente; y si no los conoce previamente, entonces no es omnisciente.

Y, por si fuera poco, la idea de que los seres humanos para poderse salvar necesitan de la gracia divina via Christi, le añadía un elemento problemático más a ese ya oscuro y complejo nudo de problemas. Como ya lo había planteado Agustín de Hipona, la doctrina cristiana sobre la acción salvífica de Cristo implica que la gracia de Dios es indispensable para que los seres humanos puedan salvarse. De otro modo, la encarnación de Cristo no hubiera sido indispensable, y la gracia divina no pasaría de ser 
un aditamento más para ayudarnos a ser buenos. Si esta fuera la perspectiva correcta, en realidad seríamos nosotros -y únicamente nosotros mismos y nosotros solos- con nuestra voluntad -y únicamente con ella, sin ningún tipo de auxilio adicional-, los que nos haríamos merecedores de la salvación o de la condenación, en virtud de nuestros propio actos buenos o malos.

Sobre este punto habría de enfocar Martín Lutero todas sus baterías. Como monje agustino, Lutero conocía muy bien la disputa de Agustín de Hipona en contra de las doctrinas que defendió el piadoso monje británico Pelagio (entre los siglos IV y V d. C.). Este último buscaba que los cristianos corrigieran sus costumbres y se preocuparan por su salvación. Él mismo, o al menos sus seguidores, llegaron a negar la existencia del pecado original, y afirmaron que la salvación o la condenación dependían por completo de la voluntad de cada ser humano. Dentro de la lógica de la doctrina voluntarista de Pelagio, la gracia divina era sólo una ayuda adicional para la acción de la voluntad, importante, sin duda, pero no indispensable.

Es probable que el molinismo semipelagiano de Calderón de la Barca haya guiado al dramaturgo para evitar ciertas palabras en su pieza dramática. Es muy significativo, en todo caso, que en La vida es sueño la palabra Dios -con mayúscula- únicamente aparezca tres veces en la Jornada Primera, catorce en la Jornada Segunda y doce en la Jornada Tercera; que el término gracia no sea utilizado; y que tampoco Calderón recurra a las palabras "Cristo", "Jesús”, "Espíritu Santo", "Paráclito", o algún otro término de ese tenor teológico. El caso es distinto para "cielo" o "cielos", cuya recurrencia adquiere el mayor protagonismo -y ello más a menudo con el sentido de "destino".

Así, por ejemplo, en la Jornada II, donde tenemos la mayor recurrencia de la palabra Dios, se trata sobre todo de exclamaciones, y los versos pertinentes son estos: "No / me estorbe nadie, que es vana / diligencia; y ¡vive Dios! / si os ponéis delante vos, / que os eche por la ventana” (vv. 226230); "Dios os guarde" (v. 366); "Si digo que os guarde Dios" (v. 373); "le diré a Dios que no os guarde” (v. 378); “¡Por Dios que lo he de probar!” (v. 442); “¡Vive Dios, que pudo ser!” (v. 446); “Al cielo y a Dios pluguiera / que a dártele no llegara" [el ser de hombre] (vv. 503, 504); "Leía / una vez en los libros que tenía / que lo que a Dios mayor estudio debe / era el hombre, por ser un mundo breve” (vv. 577-580); “ivive Dios!” (v. 678), “Gracias a Dios” (v. 779); “¡ay, Dios!” (v. 899); “Vive Dios” (v. 966); “¡Válgate Dios 
por Rosaura!” (v. 1.029); y “Válgame Dios, / qué de cosas he soñado!” (vv. $1.101,1.102)$.

No he encontrado expresiones cuya intención apuntara a la petición de auxilio divino ante situaciones que seducirían a la voluntad para que obrara mal. Dios, preferentemente, está incluido en expresiones emotivas de apóstrofe, de asombro, de imprecación, de deseo de buena fortuna, de juramento para confirmar la capacidad de acción, y de agradecimiento por un acontecimiento favorable ${ }^{27}$.

Entonces, si recordamos las seis funciones que puede desempeñar una palabra, señaladas por Roman Jakobson en su estudio sobre Lingüística y poética, Calderón de la Barca reduciría al mínimo la función referencial o extralingüística de la palabra "Dios", y ella tendería a agotarse especialmente en su función simplemente emotiva, y un poco en su función conativa (Jakobson, 2000, pp. 37-38). Todo se juega como si, para Calderón de la Barca, la voluntad de Segismundo extrajera desde sí misma, y únicamente desde sí misma, el poder para obrar el bien o para obrar el mal. Dios no interviene, o no parece intervenir, cuando la voluntad misma decide, ya sea por el acto bueno, ya sea por el acto malo.

Como lo he señalado, la intervención de Lutero vino a introducir en la discusión sobre el libro albedrío un elemento nuevo que se prestaba para malos entendidos. Para comprender mejor la situación, considero necesario recordar previamente algunos puntos.

El gran humanista Erasmo de Rotterdam (1466-1536) gozaba en Europa de un muy merecido prestigio por el cultivo de las lenguas clásicas, el griego y el latín, y había dado a conocer agudas críticas a la situación de la Iglesia. De modo que cuando Lutero inició su rebelión contra Roma, muchos creyeron que Erasmo iba a apoyarlo, entre ellos el mismo Reformador. Sin embargo, luego de un prudente silencio y al verse presionado por diversas autoridades eclesiásticas y civiles, dio a luz un escrito titulado: De libero arbitrio diatribe sive collatio, es decir, un discurso o una comparación acerca del libre albedrío. Al señalar que Lutero exigía que la argumentación teológica se atuviera a lo dicho por las Sagradas Escrituras, Erasmo examina numerosos textos bíblicos para preguntarse si en ellos se afirma o se niega el

27 Luego volveré sobre estas palabras que, a modo de maldición justificada, el rey Basilio le lanza a Segismundo: "Al cielo y a Dios pluguiera / que a dártele no llegara" [el ser de hombre] (vv. 503-504). 
libre albedrío. Llega a la conclusión de que si tomamos en cuenta la totalidad de los pasajes bíblicos, ello no nos permite decidir la cuestión: los pasajes que parecen negar el libre albedrío se neutralizan con aquellos que parecen afirmarlo. Ahora bien, cuando las Escrituras Sagradas no permiten resolver un problema, argumenta Erasmo, debemos atenernos al magisterio de la Iglesia y al sentido común; y desde ambas posiciones -magisterio y sentido común- la conclusión es que el hombre debe disponer de la capacidad para decidir por sí mismo sobre su comportamiento correcto o incorrecto.

Los biógrafos de Lutero -pienso aquí en Lucien Fevbre y en James Atkinson, por ejemplo- comentan que el golpe recibido por este ataque del gran humanista debió ser tan fuerte, que el Reformador, acostumbrado a responder de manera inmediata a los ataques, demoró un año antes de dar a conocer su respuesta. Se trata de La voluntad determinada (De servo arbitrio), o que la voluntad libre no es nada (1525), uno de los escritos más brillantes y más hermosos que hayan salido de su poderosa pluma. Con su habitual vehemencia, exclama el Reformador:

Tú, solamente tú, has llegado a discernir el punto cardinal de todo lo que actualmente está en controversia, y me echaste la mano a la garganta, por lo que te agradezco desde lo profundo de mi corazón. [. . .] De todos mis adversarios, tú eres el único que ha atacado el problema mismo, esto es, el punto esencial de mi doctrina. (IV, p. 332).

Siguiendo su interpretación de la posición de Agustín contra Pelagio, Lutero señala que la gracia divina es absolutamente indispensable para salir del pecado y alcanzar la salvación, de modo que sin ella estamos condenados irremisiblemente. De ahí el sentido literal y polémico del título mismo de la obra: Acerca del albedrío servil (De servo arbitrio). Ya desde su título, esta obra va en contravía del libre albedrío que defendían tanto Erasmo como toda la tradición católica. Para el Reformador, la voluntad humana se hallaba inclinada irremediablemente al mal como consecuencia del pecado de Adán.

Sería quizá posible leer en clave luterana esta palabra del rey Basilio a su servidor Clotaldo, cuando toma conciencia de que está triunfando la revolución encabezada por Segismundo. A pesar de todo lo que hizo para prevenir el parricidio y el regicidio, el rey Basilio piensa que "que son 
diligencias vanas / del hombre cuantas dispone / contra mayor fuerza y causa" (III, vv. 918-920). La voluntad de su hijo, el príncipe Segismundo, pecará irremediablemente. Clotaldo, en cambio, no acepta el determinismo pecador de la voluntad y, de este modo, hace eco al pelagianismo, al erasmismo y al molinismo.

Ahora bien, a diferencia de la posición filosófica que asumirá más tarde Spinoza, Lutero no estaba negando nuestra posibilidad de pecar. Por el contrario, él partía de la innegable existencia del pecado, y negaba que los seres humanos pudiéramos salir de ese estado sin la intervención de la gracia divina. Con lo cual la situación se mostraba paradójica. Porque si la razón humana no logra comprender el libre albedrío, es precisamente porque ella, desde sí misma, no logra justificar la posibilidad de pecar. La posición de Lutero no podía ser más divergente: él negaba el libre albedrío precisamente porque no podemos no pecar, y porque no estamos en condiciones de salir del estado de pecado, heredado e inevitable. Desde la perspectiva de la reflexión filosófica, puede decirse que Lutero negaba del libre albedrío precisamente aquello que la razón considera comprensible, es decir, que podamos obrar bien en virtud de nuestra propia voluntad; mientras que la razón humana niega del libre albedrío precisamente aquello que Lutero afirmaba con vehemencia, a saber, que no podemos evitar el pecado. Para el Reformador, la doctrina central de la revelación cristiana tenía que ver, en efecto, con el carácter absolutamente indispensable de la gracia divina para que la voluntad alcanzara la salvación.

$\mathrm{Al}$ suponer que Segismundo no podría no pecar -cometer al mismo tiempo dos pecados: regicidio y parricidio-, el rey Basilio dispone de varios tipos de razones que lo justifican en su decisión de encerrar a su hijo y príncipe. La primera razón es de naturaleza teológico-antropológica en clave luterana: la voluntad humana no está en libertad para evitar el pecado; la segunda, de naturaleza cósmico-esotérica: los sueños y los astros anuncian que Segismundo matará a su padre, y, la tercera, de naturaleza personal-monárquica: para su propia sobrevivencia y la de su reino, el rey deberá proteger su vida propia por cualquier medio. Aquí están las palabras con las que el rey Basilio justifica ante Astolfo y ante Estrella el encierro de Segismundo tan pronto como hubo nacido. Hado, adivinación, pronóstico, fatalidad, vaticinio, estrellas: todo esto apunta al destino de hierro impuesto sobre la voluntad humana. 
Pues dando crédito yo

a los hados, que adivinos

me pronosticaban daños

en fatales vaticinios,

determiné de encerrar

la fiera que había nacido,

por ver si el sabio tenía

en las estrellas dominio (I, vv. 730-737).

\section{El libre albedrío en La vida es sueño}

Ya hemos dibujado las líneas generales de la controversia en torno al libre albedrío. Además, y conviene señalarlo otra vez, esa controversia había llegado a introducirse en el seno mismo de la teología católica. Por su educación religiosa, por su calidad de sacerdote, por las coordenadas culturales de la España católica donde vivió y donde escribió, y por el contexto de controversia intelectual de su época, podemos comprender mejor la intención apologética de Calderón de la Barca a la hora de escribir su famosa pieza de teatro. El dramaturgo busca mostrar cómo nuestro destino no se halla escrito en el firmamento, sino que, por el contrario, disponemos de una capacidad de obrar desde una voluntad, y esa capacidad nos permite, gracias a nuestra reflexión, hacer aquello que nuestra razón nos dicta. En otras palabras: los seres humanos gozamos de un libre albedrío. Frente al fatalismo antropológico del rey Basilio, Clotaldo protesta; y esa protesta es aún más poderosa, porque, por un lado, incluye el reconocido vasallaje hacia su rey y, por otro lado y a pesar del vasallaje, el súbdito tiene el coraje de contradecir al soberano. Clotaldo comunica así su rechazo al determinismo de la voluntad, haciendo referencia a su fe religiosa:

Aunque el hado, señor, sabe

todos los caminos, y halla

a quien busca entre lo espeso

de las peñas, no es cristiana

determinación decir

que no hay reparo a su saña (III, vv. 925-930).

No niega, entonces, la idea de un destino, de un hado que logra sus designios sobre los seres humanos, pero lo que no resulta cristiano es 
aceptar la imposibilidad de oponerse al mismo. La resignación frente al destino viene a ser inaceptable para un verdadero creyente.

Ya el primer monólogo de Segismundo, en su primera décima, nos había dejado muy en claro, desde el comienzo mismo de la obra, que el problema central sería el de la libertad. ¿Qué falta he cometido, se pregunta Segismundo, para haber perdido la libertad? Es cierto que el solo hecho de nacer ya nos hace, en cierta medida, culpables. Y, en este punto, había un acuerdo entre católicos y protestantes, porque todos nacemos con la mancha del pecado original. No obstante, ello no puede ser explicación suficiente para la falta de libertad en la que se halla Segismundo. Escuchemos una vez más sus palabras:

\author{
Apurar, cielos, pretendo, \\ ya que me tratáis así, \\ qué delito cometí \\ contra vosotros naciendo; \\ aunque, si nací, ya entiendo \\ qué delito he cometido; \\ bastante causa ha tenido \\ vuestra justicia y rigor, \\ pues el delito mayor \\ del hombre es haber nacido (I, vv. 103-112).
}

Y luego de algunas consideraciones para reforzar su pregunta, desarrolla las cuatro hermosas décimas en las que señala, en un movimiento descendente, cómo las aves (del cielo), las bestias (de la tierra), los peces (del mar) y hasta los mismos ríos gozan de una gran libertad, mientras que él se halla encadenado. Cada décima termina con el estribillo de una misma pregunta en forma de inolvidable ritornello: “¿tengo menos libertad?”. El prisionero no acepta la limitación física de su cárcel de piedra; y él mismo es consciente de una paradoja extraordinaria: no tiene libertad efectiva, $y$ sin embargo, sí tiene albedrío. Recordemos algunos de sus versos:

\footnotetext{
Nace el ave, $y$, con las galas que le dan belleza suma, apenas es flor de pluma $[\ldots]$ ¿y teniendo yo más alma, tengo menos libertad?
} 
Nace el bruto, y, con la piel que dibujan manchas bellas, apenas signo es de estrellas [...]

¿y yo, con mejor instinto, tengo menos libertad?

Nace el pez, que no respira, aborto de ovas y lamas, y apenas bajel de escamas [...]

¿y yo, con más albedrío, tengo menos libertad?

Nace el arroyo, culebra que entre flores se desata, $\mathrm{y}$ apenas, sierpe de plata [...]

¿y teniendo yo más vida, tengo menos libertad? (I, vv. 122-124; 130-134; 140-144; 150-154; 160-161).

Y Segismundo termina, luego, con una verdadera imprecación. Ella brota a modo de torrente volcánico desde su pecho desgarrado, y para ello retoma al final, en orden inverso, es decir, ascendente, los cuatro seres mencionados antes, a saber, las entidades inanimadas, los peces, los brutos y las aves:

\author{
¿Qué ley, justicia o razón \\ negar a los hombres sabe \\ privilegio tan süave, \\ excepción tan principal, \\ que Dios le ha dado a un cristal, \\ a un pez, a un bruto y a un ave? (I, vv. 166-171)
}

Conviene recordar que para un ejercicio adecuado de nuestro libre albedrío, la doctrina cristiana considera que es condición fundamental el que sepamos tomar clara distancia frente a las apariencias de este mundo. Para este fin, resulta indispensable comprender la fugacidad e inconsistencia de todo lo que existe. La visión platónica de un mundo conformado por meras sombras de las ideas eternas es presentada por Calderón de la Barca como la experiencia necesaria para alcanzar una verdadera libertad. Porque si bien es cierto que contamos con el libre albedrío, éste no nos asegura de inmediato nuestra condición de seres libres: estamos expuestos a ser encadenados por la necesidad que reina en la naturaleza. En otras palabras: 
el libre albedrío no debe confundirse con la verdadera libertad, ya que es únicamente la condición necesaria para la misma, pero no su condición suficiente. El libre albedrío nos otorga la posibilidad de ser libres, pero también es él quien hace posible que perdamos nuestra libertad cuando no obedecemos a nuestra razón.

Si el título de la obra es La vida es sueño, ello se debe a que su propósito apologético no busca proclamar únicamente que los seres humanos seamos libres por naturaleza, sino, en cierta forma, todo lo contrario: que somos libres precisamente en la medida en que logremos tomar distancia de la naturaleza, en la medida en que experimentemos, de manera profunda, la radical caducidad de esa naturaleza, de ese mundo. Solo quien logra tomar esa distancia mediante la reflexión está en condiciones de convertir las necesidades que impone la naturaleza en ocasiones para el ejercicio de su libertad.

Resulta interesante señalar cómo la tradición budista comparte esta misma idea. Es necesario convencerseíntimamente de la total inconsistencia de todo lo que existe, de su radical caducidad, para llegar a desprendernos de nuestro propio yo y a liberarnos así del sufrimiento. Arthur Schopenhauer (1788-1860), lector de obras de Calderón y de obras del budismo, pudo por esto emprender un proyecto serio de síntesis, no únicamente entre esas dos obras, sino además, y más atrevidamente, entre raíces centrales de la filosofía -platonismo y kantismo- y las doctrinas budistas ${ }^{28}$.

Es de nuevo el monólogo de Segismundo, al final de la Segunda Jornada, luego de haber retornado a su prisión en la torre, donde Calderón de la Barca nos hace ver la necesidad impostergable de tener una experiencia primordial en gran medida dolorosa: la de que todo lo que existe no es más que un sueño -pasajero, liviano, ilusorio, incontrolado. Es precisamente a partir de la conciencia de esa desgarradora experiencia, como Segismundo recapacita y asume el control de sus actos:

Es verdad; pues reprimamos

esta fiera condición,

esta furia, esta ambición,

por si alguna vez soñamos;

y sí haremos, pues estamos

28 Véase sobre este tema el libro de Henry W. Sullivan sobre Calderón de la Barca en Alemania. 
en mundo tan singular, que el vivir sólo es soñar; y la experiencia me enseña que el hombre que vive sueña lo que es, hasta despertar (II, vv. 1163-1172).

Un vez llegados aquí, no puedo menos que invitar al lector para que termine de leer todo este famoso monólogo, de cadencia inolvidable, cuyas estrofas finales han llegado a convertirse casi en un lugar común. Más que un comentario, merecen una lectura de "rumiante", como aconsejaba Nietzsche:

\author{
Yo sueño que estoy aquí \\ destas prisiones cargado, \\ y soñé que en otro estado \\ más lisonjero me vi. \\ ¿Qué es la vida?, un frenesí; \\ ¿qué es la vida?, una ilusión, \\ una sombra, una ficción, \\ y el mayor bien es pequeño; \\ que toda la vida es sueño, \\ y los sueños, sueños son (II, vv. 1193-1202).
}

Si distanciarse del mundo -o, para utilizar la expresión de su contemporáneo francés René Descartes, "alejar el espíritu de los sentidos" (1982-1983, p. 104) - resulta indispensable para alcanzar la verdadera libertad, conviene preguntarse: ¿y de la fortuna qué?, ¿acaso la doctrina católica pretendía negar la existencia de esa diosa impredecible y caprichosa, figurada por su rueda o ruleta que asciende y desciende, una y otra vez, de manera interminable? Por supuesto que no, y Calderón de la Barca se cuida muy bien de señalarlo. Para este objetivo, el dramaturgo se sirve de la figura del rey Basilio, el padre de Segismundo.

Como el nacimiento de Segismundo había causado la muerte de su madre -un primer indicador factual de su naturaleza pecaminosamente criminal-, los augurios le habían informado al rey Basilio el destino fatal de su hijo, quien llegaría a ser un parricida, un regicida y un tirano que haría sufrir a su pueblo. Y, hasta cierto punto, ese mal augurio se estaba cumpliendo cuando Segismundo fue liberado por su padre para que probara su capacidad de gobierno. En gran medida, el rey estaba tentando al destino, y por ello el resultado de la liberación fue desastroso: Segismundo da muerte a un 
criado arrojándolo por la ventana, intenta violar a Rosaura y llega a herir a Clotaldo cuando éste sale en su defensa. Por creer en el destino, y también por intentar contradecirlo, el rey Basilio termina por facilitar la tarea a la implacable diosa Fortuna. He aquí, entonces, una de las enseñanzas de la pieza de Calderón de la Barca: si bien es cierto que nuestro destino no se halla escrito en las estrellas, cuando creemos en él y tratamos de contrarrestarlo, terminamos siendo sus cómplices. La maldición que para el rey Basilio se impone sobre su hijo, el rey la considera al mismo tiempo como una maldición justificada. En sus palabras: "Al cielo y a Dios pluguiera / que a dártele no llegara” [el ser de hombre] (II, vv. 503-504). El rey no se da cuenta de que él mismo está coadyuvando -verdadero cómplice-en el cumplimiento del destino fatal y maldito de su hijo Segismundo. El rey no solo lee en las estrellas la fortuna de su hijo, sino que culposamente colabora para convertir esa fortuna en su destino.

Aquí llegan, finalmente, las conclusiones ético-antropológicas de $\mathrm{La}$ vida es sueño: si bien no podemos negar que la fortuna existe, tenemos sin embargo la manera de apropiarnos de ella para convertirla en ocasión para el cumplimiento libre de nuestros deberes. Porque, en realidad, una cosa es la fortuna, es decir, aquello que nos acontece sin que podamos predecirlo ni evitarlo, y algo muy distinto es el destino, esa fuerza que se nos impone y que anula nuestra libertad. La primera es una condición involuntaria de nuestra existencia, mientras que la segunda es una creación voluntaria de nuestra errada imaginación. La libertad se alcanza, en efecto, cuando logramos convertir nuestra fortuna impuesta en oportunidad para realizarnos libremente. La doctrina es, así, bien clara: la libertad no debe confundirse con el libre albedrío, ya que éste último es solo la condición necesaria para el logro de la libertad, pero no la condición suficiente de la misma; y la fortuna no debe confundirse con el destino, porque este último anula nuestra libertad. No nacemos libres, pero estamos llamados a serlo, y para ello es indispensable que nos liberemos del apego a las cosas del mundo; que comprendamos la caducidad de ellas, y que tomemos conciencia de cómo esas cosas están ahí únicamente como ocasiones y oportunidades para que realicemos nuestro verdadero destino de seres libres. De esa manera, de acuerdo con La vida es sueño, Calderón de la Barca ha dramatizado, de manera bella y contundente, el siguiente principio ético 
del catolicismo tridentino de la Contrarreforma: lo que se nos presenta como impuesto, como un destino, podemos convertirlo en fortuna, es decir, en posibilidad para la acción. 


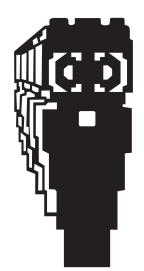

